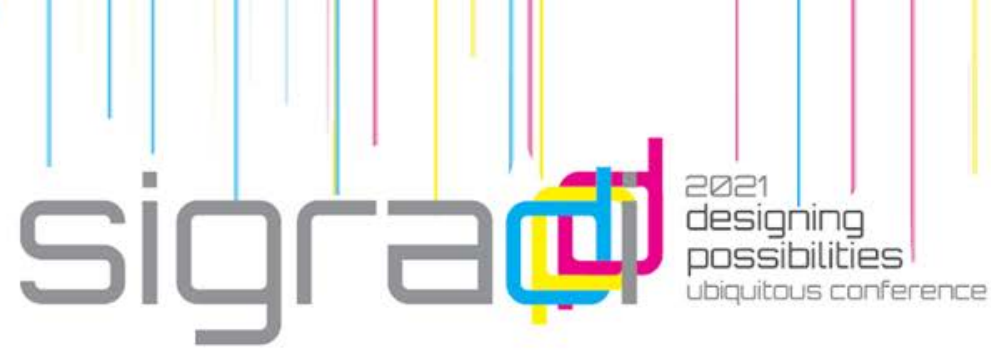

\title{
Women in Digital Fabrication: An analysis of Women in Protagonist Roles Inside University Laboratories
}

\author{
Thaciana Belarmino, Kátia Araújo, Leticia Teixeira Mendes, Kaio Lima \\ Universidade Federal de Pernambuco, Brasil \\ thaciana.belarmino@ufpe.br \\ katia.araujo@ufpe.br \\ leticia.mendes@ufpe.br \\ kaio.lima@ufpe.br
}

\begin{abstract}
This paper intents to bring into the technology field a debate regarding gender perspective. We analyze the professional qualifications and trajectories of three women who have distinct experiences and functions working with digital fabrication at two Brazilian universities' laboratories. The semi-structured interviews were executed remotely along with data collection over the internet. In the analysis is debated the protagonism of these professionals inside the laboratories, the role they play in the dissemination of this technology and on the reproduction of technological knowledge among women around different regions of Brazil.
\end{abstract}

Keywords: Digital Fabrication, Women, Equity, University, Gender.

\section{Introdução}

Os dados da Pesquisa Nacional de Amostra por Domicílio Contínua (PNAD, 2019), relativos à frequência escolar, indicam que as mulheres possuem maior instrução que os homens. Destacamos que o acesso à educação se dá de forma desigual entre as mulheres, quando considerados os indicadores de raça e classe. Ainda que estejam em vantagem em relação ao acesso ao ensino superior, as mulheres enfrentam barreiras em campos de CT\&I. Em 2019, as mulheres representavam apenas $13,6 \%$ dos matriculados em cursos de graduação presencial na área de Computação, Tecnologias da informação e Comunicação (Censo da Educação Superior, 2019). A participação minoritária nessas áreas de formação, tal como expressado neste dado, nos parece um 
grande desafio quando se pensa a inserção feminina em carreiras tecnológicas.

A atuação das mulheres no universo da tecnologia é de extrema relevância quando se busca uma produção de saberes que superem o sexismo, o racismo e o etnocentrismo, e para a construção de conhecimentos que atendam à sociedade de forma inclusiva, ética e equilibrada (Lima, 2017).

A partir desta ideia, o presente artigo busca fazer discussão relativa às trajetórias de protagonistas em espaços de produção de design e tecnologias de fabricação digital de algumas universidades brasileiras - carreiras estas consideradas de prestígio - com foco na equidade de gênero. O recorte do estudo se concentra em laboratórios de fabricação digital coordenados por mulheres. O objetivo do trabalho é projetar discussões sobre a perspectiva de gênero, através de uma análise das trajetórias de algumas das mulheres que vivenciam esses laboratórios atuando em posições distintas. Assim, objetivase contribuir para o tema instigando reflexões sobre o processo que ampliou a participação feminina no citado contexto e os frutos desta participação no campo da ciência e tecnologia, em especial, das tecnologias de fabricação digital.

A representatividade de mulheres que trabalham com as tecnologias de fabricação digital e prototipagem rápida, provavelmente reflete a subrepresentação feminina nos diversos campos da ciência, tecnologia e inovação (CT\&I). Uma busca que realizamos no site do CNPQ no corrente ano ${ }^{1}$ revelou que, dos trinta e quatro grupos de pesquisas de fabricação digital e prototipagem, apenas doze contém pelo menos uma mulher na liderança. $E$ dos trinta e quatro grupos de pesquisa, sete são organizados exclusivamente por mulheres. Percebe-se também que mais de $90 \%$ dos grupos com pelo menos uma líder estão concentrados nas áreas de design e arquitetura e urbanismo. Os dados permitem inferir que, apesar de ainda representar espaço subocupado por mulheres, a fabricação digital tem sido, talvez mais que outros campos das tecnologias digitais, permeável à participação feminina.

${ }^{1}$ http://dgp.cnpq.br/dgp/faces/consulta/consulta parametrizada.jsf 
ganhamos controle do design e dos frutos do nosso trabalho. Mas esta é uma agenda revolucionária [...]. (Hubbard, 1983, VII, tradução nossa²).

A agenda revolucionária citada por Hubbard é o ponto de partida para a elaboração dos questionamentos aqui levantados. Questões que se ancoram tanto na necessidade de se dar visibilidade à participação feminina nos redutos onde esta presença é menos cogitada (Perrot, 2007), como laboratórios de tecnologia; quanto no pressuposto de que é fundamental revelar as dinâmicas de poder nas relações de gênero em tais espaço.

Ressaltamos também a importância de trabalhar com a perspectiva da pesquisa qualitativa, em especial, a estratégia de analisar trajetórias de vida (neste caso trajetórias profissionais de mulheres) representativas dos processo e relações de poder que se estabelecem em espaço nos quais uma ótica masculina seria hegemônica e dominante (Queiroz, 1988).

\section{Metodologia}

Esse estudo consiste em uma investigação exploratória, parte de uma dissertação em andamento. Aqui apresentamos dados de entrevistas semi estruturadas realizadas via Google Meet e informações obtidas na internet. Inicialmente, planejou-se visitas aos laboratórios para experienciar a vivência desses espaços tecnológicos. Como imposição da pandemia do COVID-19, entretanto, as visitas foram substituídas por entrevistas remotas.

Foram entrevistadas três mulheres profissionais que exercem protagonismo em dois laboratórios de fabricação digital de duas universidades públicas brasileiras (Sul e Nordeste). As entrevistadas pertencem a diferentes gerações, existindo entre elas vínculos que se estabeleceram via formação e experiência de formação.

Os Laboratórios aos quais se vinculam as entrevistadas são legatários, cada um a seu tempo, de certa disseminação de ideias sobre tecnologia digital que vieram do MIT - Massachusetts Institute of Technology, e se enraizaram em diferentes regiões do Brasil.

A revisão de literatura abordou as temáticas da fabricação digital e relações de gênero e poder. Foram coletados dados qualitativos como informações

\footnotetext{
${ }^{2}$ Technology is part of our culture; and, of course, our culture, which is male dominated, has developed technologies that reinforce male supremacy. Can this be changed by women becoming more involved with technology -- not only as its users, but as its inventors, makers, and repairers? [...] Only to the extent that we gain control of the design and fruits of our labor. But that is a revolutionary agenda [...].
} 


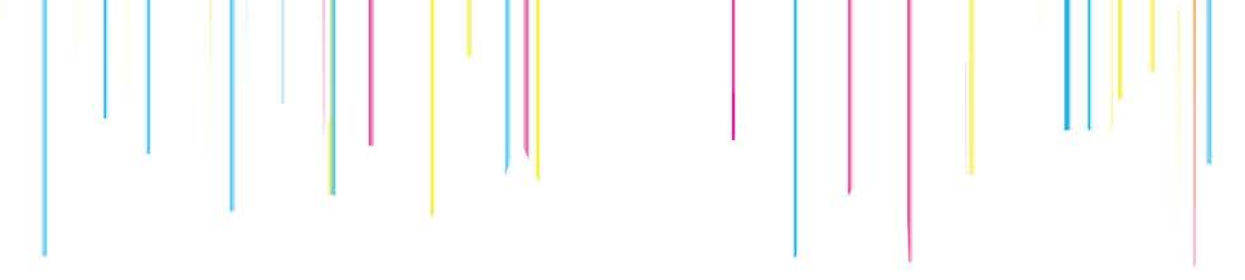

sobre a estrutura e organização do trabalho dentro dos laboratórios, acesso às tecnologias de produção digital e trajetórias de vida das entrevistadas. $\mathrm{O}$ protocolo executado incluiu três partes, sendo elas: "Trajetórias de mulheres na Tecnologia e disseminação de conhecimento", "O papel dos laboratórios de fabricação digital na consolidação do conhecimento sobre o tema" e "Desafios e Esperanças".

\section{Resultados}

O maquinário de Fabricação Digital e Prototipagem Rápida têm ganhado espaço nas universidades como ferramenta pedagógica para desenvolvimento de projetos. A investigação aborda três entrevistas (foi utilizado nomes fantasia para se referir às entrevistadas a seguir) realizadas respectivamente com: a professora doutora Maria, que coordena a rede de laboratórios A na Universidade Federal de Santa Catarina - UFSC; a professora doutora Joana integrante do laboratório B, da Universidade Federal de Pernambuco - UFPE; e a arquiteta recém formada Clara, egressa do laboratório B da UFPE. Nos tópicos que se seguem, discutimos o processo de formação das protagonistas, associados ao compartilhamento do saber tecnológico; alguns aspectos envolvidos na consolidação desses aprendizados e as expectativas e os desafios enfrentados nesses espaços.

\subsection{Trajetórias de mulheres na Tecnologia e disseminação de conhecimento}

A professora Maria teve seu primeiro contato com tecnologias digitais nos Estados Unidos, onde morou após se graduar em Arquitetura e Urbanismo em 1986. Lá, ela trabalhou como arquivista em um escritório de arquitetura e, através da sua curiosidade, buscou aprender sobre os softwares que estavam surgindo na época. Maria relata que sempre passava por um colega de trabalho que utilizava um computador e sempre se questionava "o que é um computador?" O colega se dispôs a lhe ensinar e, assim, ela passou a desenvolver apresentações para clientes utilizando a nova ferramenta. Estavase, então, nos primórdios do uso de computadores desktop para fins de uso profissional nesta área. Quando retornou ao Brasil, ela percebeu que dispunha de uma bagagem que os outros profissionais ainda não possuíam.

"Eu sempre fui ligada na tecnologia [...]. Eu gostava muito, sempre gostei de eletrônica. Eu sempre fui maker, meu avô era maker, então aqui em casa todo 
mundo é maker. [...] Então a gente sempre teve essa curiosidade de a gente mesmo fazer as coisas" (Maria, 2021).

Em sua fala, a entrevistada discorreu sobre o que percebemos como uma cadeia de influência em termos de formação profissional envolvendo mulheres. Ela menciona que seu doutorado - desenvolvido no Laboratório C, integrante da Universidade Estadual de Campinas - UNICAMP, Sudeste do Brasil, realizado sob a orientação da Prof. ${ }^{a}$ Dra. Carolina, uma das pioneiras quanto à formação em tecnologia de fabricação digital no país - foi de extrema importância para sua formação, o que possibilitou a criação do laboratório A UFSC, sob sua coordenação. Por sua vez, o Laboratório da UFSC coordenado pela professora Maria tem também contribuído significativamente para a disseminação de conhecimento sobre tecnologias de fabricação digital e formação de novos profissionais distribuídos em alguns estados do Brasil. Além de diversos alunos trabalhando com o tema, tanto no ambiente acadêmico quanto no mercado de trabalho, a atuação de Maria contribuiu também para formação de outros docentes, a exemplo da prof. ${ }^{a}$ Júlia pesquisadora que implementou o laboratório de fabricação digital B na UFPE, Nordeste do Brasil.

No comando do laboratório $B$, além da prof. ${ }^{a}$ Júlia, existem mais três professores vinculados à UFPE. Dentre eles está a professora Joana, que construiu uma trajetória de formação profissional diferente da apresentada pela prof. ${ }^{a}$ Maria. Formada em Desenho Industrial pela UFPE em 1999, Joana acredita que seu interesse por qualquer tipo de máquina contribuiu para sua atuação em tecnologia hoje. Até antes de sua integração ao citado Laboratório $B$, ela não possuía nenhuma formação específica na área, mas apenas interesse pessoal pelo tema. Informou ainda que, a partir do contato com os colegas, no contexto do trabalho, foi aprendendo sobre as técnicas desenvolvidas no Laboratório $B$ e beneficiando-se também de capacitações, cursos para docentes e oficinas, na medida em que o espaço foi sendo consolidado. A trajetória de formação desta docente revela o poder de disseminação do conhecimento em questão, proporcionado pela existência desta organização (o citado laboratório B)

Joana conta que alguns alunos egressos que participaram do laboratório $B$, hoje trabalham neste campo tecnológico específico. Percebe-se que 0 interesse pelas técnicas de fabricação digital e prototipagem rápida que o laboratório desperta e alimenta nos alunos os vai acompanhando em outras etapas de suas carreiras profissionais. Na entrevista, ela afirma que alguns alunos têm vontade de montar seus próprios laboratórios de tecnologia, mas que Ihes faltam recursos financeiros. 
Por sua vez, a entrevistada Clara, arquiteta e urbanista, vivenciou o espaço do laboratório B na perspectiva de uma estudante de graduação. Ela aponta sua experiência no Programa Institucional de Bolsas de Iniciação Científica PIBIC como ponto de partida para exploração de uma gama de softwares aplicados à arquitetura. Quando fez intercâmbio na Austrália, ela teve contato com modelagem paramétrica. Clara acredita que esse intercâmbio foi um marco na sua construção acadêmica, expandindo suas possibilidades de atuação em arquitetura e urbanismo e exploração de ferramentas digitais. Os campos da arquitetura e tecnologia vem instigando e entrevistada, que já participou de diversos cursos sobre parametrização, design generativo e modelagem avançada, tanto na UFPE quanto em outras instituições. Ela afirma que um workshop promovido pela professora Júlia abriu sua mente para pensar no tema do seu TCC.

\subsection{O papel dos laboratórios de fabricação digital na consolidação do conhecimento sobre o tema}

A professora Maria atua no laboratório A (vinculado ao curso de Design da UFSC) desde sua criação, em 2013. A rede do laboratório A possui unidades espalhadas em outras cidades do mesmo estado. No cotidiano das atividades acadêmicas deste laboratório, cada estudante bolsista é responsável por um setor de tecnologia, organizando os agendamentos e atendimentos de quem irá utilizar as máquinas. Os setores são, respectivamente, impressão 3D, corte à laser e maquinário de Controle numérico computadorizado - CNC.

Maria afirma que ter sucesso nesse espaço de trabalho significa ter reconhecimento de sua pesquisa, êxito nos produtos desenvolvidos, inserção no mercado e, sobretudo, benefício para seus alunos, oportunizando-os conquistar empregos. Como coordenadora do laboratório A, ela afirma que as decisões sempre são tomadas em colaboração com os outros membros. As dificuldades apontadas na atuação junto ao laboratório referem-se à questão dos recursos para conseguir mais bolsas e para manutenção das máquinas.

A professora Joana atua no laboratório B (vinculado ao Departamento de Expressão Gráfica da UFPE) desde sua criação, em 2016. O laboratório objetiva ser, sobretudo, uma ferramenta pedagógica de apoio a disciplinas, projetos de extensão e iniciação científica. $O$ acesso ao laboratório se dá através de disciplinas ou pesquisas atreladas a algum docente. Nessas atividades, o próprio aluno pode manipular as máquinas de produção digital e desenvolver experiência prática.

Joana aponta que a liberdade projetual para desenvolver e criar mais livremente, dentro das possibilidades do laboratório é muito positiva. Como obstáculo envolvido na atuação em ambientes tecnológicos, a entrevistada cita 
a dificuldade de se manter atualizada com os diversos softwares que vão surgindo e se aprimorando.

Já Clara, participou como estudante em diversas iniciativas do laboratório B. Para ela, "bem estar" no espaço de trabalho é fruto do aspecto colaborativo, que oportuniza a criação e o estímulo dos colegas, além do produto em si. A arquiteta afirma que a otimização dos processos e seus benefícios foi uma das motivações que a levou a atuar na tecnologia. Entretanto, ela considera difícil encontrar vagas no mercado de arquitetura e urbanismo que instrumentalizem ferramentas de produção digital, tais como softwares paramétricos.

\subsection{Desafios e Esperanças}

As três entrevistadas afirmaram que se consideram feministas, apesar de apresentarem reticências quanto a certos entendimentos do feminismo. A professora Maria acredita que a mulher deve ser respeitada e ter a oportunidade de inserção igualitária no mercado de trabalho. A professora Joana também afirma que se considera feminista no que diz respeito à dimensão de respeito e igualdade de oportunidades. Por sua vez, a arquiteta Clara pontua que tem muito o que aprender sobre o tema feminismo e relembra que desde criança enxergava como errônea a rotulação de funções/atribuições relacionadas a estereótipos de gênero.

Por sua vez, quando perguntado sobre quais seriam os maiores desafios para a inserção feminina no mercado tecnológico, as entrevistadas pontuaram diferentes questões. Maria caracterizou a abertura para as meninas como um desafio, barreira que programas como o "Meninas Super Cientistas" tentam melhorar. Ela cita o paradigma de que as meninas às vezes começam involuntariamente a acreditar que não servem para determinado campo. A informação errônea de que certa profissão "não é de menina" junto com o estereótipo aprendido na infância contribuem para esse tipo de pensamento. 'Lá no laboratório não existe o 'esquisito', a gente entende as pessoas como elas vêm", afirma a entrevistada. Por outro lado, Joana acredita que um grande desafio das mulheres na carreira tecnológica é conseguirem começar e finalizar seus cursos, enfrentando o desafio de conciliar vida pessoal, estudos, família e atividades domésticas. Já Clara considera que fazer com que as meninas vejam carreiras tecnológicas como possibilidade, seja um dos desafios a se superar atualmente. Ela aponta, também, que se inspira muito nas mulheres envolvidas com tecnologias que conheceu em sua formação, como expressão de representatividade na área.

\section{Discussões}


Neste trabalho abordamos centralmente três gerações de mulheres envolvidas em carreiras de prestígio no campo das tecnologias de Fabricação Digital, particularmente suas trajetórias de formação e de desenvolvimento profissional. Da apreciação de suas declarações, destacamos o aspecto de estarem, as trajetórias profissionais dessas mulheres, inter-relacionadas por vínculos que se dão a partir da disseminação de conhecimento tecnológico através de uma rede caracterizada pelo protagonismo feminino.

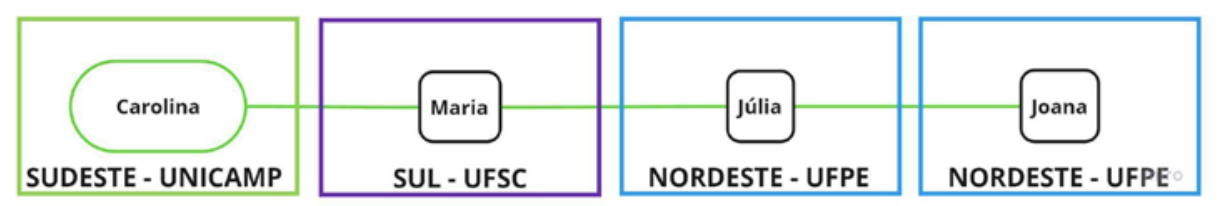

Figura 3. Diagrama esquemático de conexões entre as profissionais envolvidas com a rede de conhecimento estabelecida sobre Fabricação Digital e criação de laboratórios universitários no recorte da pesquisa. Fonte: Os autores, 2021.

As entrevistadas apresentam perfis de formação representativos de mulheres pesquisadoras em tecnologia de suas respectivas gerações. Sendo pesquisadora mais madura, a pesquisadora Maria conta treze anos de carreira e experienciou o início da aplicação de softwares na arquitetura e urbanismo; já Joana, representa uma geração de pesquisadoras que tiveram formação em laboratórios de universidades brasileiras criados com a contribuição de quadros desta primeira geração. A terceira informante, Clara, representa uma geração de pesquisadoras que já tiveram assegurado um sólido conhecimento em tecnologia de fabricação digital pelos laboratórios instalados nas suas próprias universidades. Em sua fala, Clara também nos revelou a exiguidade de postos de trabalho que lhe permitam utilizar mais plenamente as tecnologias aprendidas.

\section{Conclusão}

As mulheres vêm assumindo vários campos de luta, sejam eles políticos, sociais, econômicos, culturais, tecnológicos e educacionais, buscando visibilidade, respeito e direitos que Ihes são apagados. Sendo assim, o espaço de legitimação dentro da tecnologia tem sido buscado de diversas formas, uma vez que o setor tecnológico se apresenta como uma oportunidade promissora de independência financeira e reconhecimento de status social, que muitas vezes as liberta inclusive de violências domésticas. O presente artigo almejou ser um registro do protagonismo feminino em carreiras de prestígio, dada a 
importância de trazer visibilidade ao movimento de mulheres protagonistas em instituições onde a dominação masculina opera (Perrot, 2007). Aqui, alimentase o interesse na transformação da visão tradicional e limitante do papel da mulher nos diversos âmbitos sociais: de negligenciado e negligenciável para ativo e resistente! Portanto, destacamos que as protagonistas do estudo se apresentam como agentes de resistência e transformação dentro do campo onde atuam: o espaço tecnológico que lhes é constantemente negado.

Diante de três trajetórias diferentes aqui apresentadas, concluímos que, ainda que escasso o número de mulheres nas posições de prestígio nos campos da tecnologia, as mulheres protagonistas cooperam para a alimentação de uma rede de conhecimento para o empoderamento feminino, criando raízes em diferentes regiões do Brasil. Além disso, observa-se também que as suas próprias atuações profissionais servem de símbolo, incentivando outras meninas a enxergarem e acreditarem na possibilidade de trilhar a carreira tecnológica.

Os próximos passos que pretendemos contemplar na investigação do tema se apoiam no pensamento e contribuições metodológicas de Londa Schiebinger (2014): o método de análise de sexo e gênero. Mais especificamente, atentaremos ao aspecto de gendramento nos projetos de pesquisa e produtos tecnológicos eleitos pelos laboratórios, identificado os princípios privilegiados. A esse respeito, a autora pontua ser importante a abordagem de três aspectos centrais: a) repensar os modelos de referência do projeto/produto (atentando-se à negligência do feminino nos modelos de ciência); b) repensar prioridades de pesquisa (indagando-se qual a intenção do projeto e a quem atende); c) analisar fatores que intersectam sexo e gênero (e assim refletindo-se sobre os próprios produtos de pesquisa, e produtos tecnológicos gerados).

Agradecimentos. À Coordenação de Aperfeiçoamento de Pessoal de Nível Superior (CAPES) pelo recurso de bolsa à mestranda pesquisadora. Às profissionais entrevistadas que contribuíram com seus relatos e histórias inspiradoras.

\section{Referências}

Doyle, S.; Forehand, L.; Senske, N. (2017). Computational Feminism: Searching for Cyborgs. In: Proceedings of the 2017 Association for Computer Aided Design in Architecture (ACADIA) Conference, 2041 Duff Ave., 232-237. http://papers.cumincad.org/data/works/att/acadia17_232.pdf.

IBGE. (2019). Pesquisa Nacional por Amostra de Domicílios (PNAD). https://www.ibge.gov.br/. 
Hubbard, R. (1983). Prefácio. In J. Rothschild, Machina ex dea: Feminist perspectives on technology. (pp. VII-VIII). Pergamon Press.

Lima, B. (2017). Políticas de equidade em gênero e ciências no Brasil: Avanços e desafios. 1 recurso online (370 p.). Tese (doutorado) - Universidade Estadual de Campinas, Instituto de Filosofia e Ciências Humanas, Campinas, SP. http://www.repositorio.unicamp.br/handle/REPOSIP/322609.

MEC. (2019). Instituto Nacional de Estudos e Pesquisas Educacionais (Inep). Censo da Educação Superior 2019. Brasília: Inep.. https://download.inep.gov.br/educacao_superior/censo_superior/documentos/202 O/Apresentacao_Censo_da_Educacao_Superior_2019.pdf.

Perrot, M. (2007). Minha História das Mulheres. Tradução de Ângela M. S. Corrêa. São Paulo: Contexto.

Queiroz, M. I. P. de. (1988). Relatos orais: do "indizível" ao "dizível". In: Queiroz, M. I. P. de; Simson, O. de M. Von. Experimentos com histórias de vida: Itália-Brasil. (pp. 14-43). São Paulo: Vértice.

Schiebinger, L. (2014). Expandindo o kit de ferramentas agnotológicas: Métodos de Análise de Sexo e Gênero. In Revista Feminismos, v.2, n.3. 